\title{
Comparison of EG/AD/S and EG/AD model ice properties ${ }^{\dagger}$
}

\author{
Jung-Hyun Kim ${ }^{1}$ and Kyungsik Choi ${ }^{{ }^{*}}$ \\ ${ }^{1}$ Department of Ocean Engineering, Korea Maritime University, Busan, 606-791, Korea
}

(Manuscript Received November 3, 2010; Revised December 5, 2010; Accepted January 21, 2011)

\begin{abstract}
EG/AD/S type model ice was originally selected as the primary model ice material for the MOERI ice tank in Korea. The existence of a sugar component in the EG/AD/S mixture may cause a serious maintenance problem. In order to understand the influence of sugar in the original model ice, a series of tests with EG/AD/S and EG/AD model ices were performed, and their material properties compared. Because the target strength of model ice in the full-scale MOERI ice tank is expensive and difficult to control, tests were performed under cold room conditions using a miniature ice tank. This paper describes the material properties of EG/AD/S and EG/AD model ices, such as flexural strength, compressive strength and elastic modulus. In order to obtain the desired strength and stiffness levels for the model ice, a warm-up process was introduced.
\end{abstract}

Keywords: Compressive strength; EG/AD/S and EG/AD model ice; Flexural strength; MOERI ice tank; Warm-up process

\section{Introduction}

Full-scale field measurements are important for the construction of Arctic ships and offshore structures however, the full-scale tests in ice-covered sea are usually very expensive and difficult. Model test in a refrigerated ice model basin may be used as a substitute method for the difficult full-scale field tests. One of the main issues when performing model tests in an ice model basin is the selection of a model ice material that follows the appropriate similitude law between the prototype and model scales. Among various material properties of model ice, the most important is the ratio of the elastic modulus to the flexural strength of the model ice. Usually, a $E / \sigma_{f}$ ratio in the range of $2,000 \sim 5,000$ is needed for the model ice to be suitable in many ice tanks [1].

The first Korean ice model basin facility for testing the ice performance and ice load estimations on ships and offshore structures under an Arctic environment,

tThis paper was presented at the $9^{\text {th }}$ ISOPE Pacific/Asia Offshore Mechanics Symposium, Busan, Korea, November 2010.

"Corresponding author. Tel.: +82-51-410-4324, Fax.: +82-51-403-4320. E-mail address: kchoi@hhu.ac.kr.

Copyright @ KSOE 2011. was completed at the MOERI (Maritime and Ocean Engineering Research Institute) in late 2009. The MOERI ice tank is equipped with a square type basin, which has a trimming tank, an $\mathrm{X}-\mathrm{Y}$ directional main carriage, a service carriage and refrigerating system, etc. The size of the main basin is 42,32 and $2.5 \mathrm{~m}$ long, wide and deep respectively. Details of the MOERI ice tank have been described previously [2].

Collaboration between the MOERI and NRC-IOT of Canada helped in the decision to use EG/AD/S type model ice in the new MOERI Ice Model Basin [3]. The MOERI ice model basin initially adopted the NRC-IOT EG/AD/S model ice because it may provide a good scaling of mechanical properties of columnar sea ice. However, it was reported that the sugar component of the EG/AD/S solution may cause a maintenance problem due to organic bacteria hence, the EG/AD model ice was later chosen for the MOERI ice tank.

This paper focused on testing the material properties of both $\mathrm{EG} / \mathrm{AD} / \mathrm{S}$ and $\mathrm{EG} / \mathrm{AD}$ model ices. In order to understand the influence of sugar in the original EG/AD/S model ice and find a possible substitute for sugar, a series of tests with two types of model ice 
were performed and with the results compared. The measured mechanical properties of EG/AD/S and EG/AD model ices included flexural strength, compressive strength and elastic modulus.

\section{Test procedures}

\subsection{Preparation of model ice specimen}

A cold room designed for ice mechanics research was used to measure the elastic modulus and flexural strength of the model ices. A digitally controlled UTM (universal testing machine), portable push-pull spring gauge and a uni-axial compression test apparatus were used to carry out the cold room tests $(4 \mathrm{~m} \times 6 \mathrm{~m} \times 2.6 \mathrm{~m})$.

Two model ice specimen types, i.e., EG/AD/S and EG/AD model ices, were prepared to evaluate the influence of sugar. As described by Timco [4], the EG/AD/S model ice was made by the additions of ethylene glycol $(0.46 \%)$, aliphatic detergent $(0.032 \%)$ and sucrose $(0.039 \%)$ to fresh water.

The freezing procedures used in the cold room were different from those in an ice model basin in many respects. To reduce the gap in the test results obtained via different freezing procedures, a miniature ice tank $(120 \times 75 \times 50 \mathrm{~cm})$ was fabricated to simulate the environment of an actual ice model basin (Photo. 1). In the miniature ice tank, the model ice sheet grew up to $30 \mathrm{~mm}$ at $-18^{\circ} \mathrm{C}$ for 6 hours. When the desired ice thickness was achieved, the air temperature in the cold room was set to $0^{\circ} \mathrm{C}$, with the warm-up process allowed to proceed for about 6 hours. This warm-up process reduced the strength of the model ice. Fig.1 shows the typical variations in the air and water temperatures in the cold room over time. The warm-up process was checked every 2 hours.

\subsection{Mechanical properties}

In an ice model basin, the flexural strength and Young's modulus of model ice are generally measured through a cantilever beam test. The flexural strength can be measured by a push-pull gauge or LVDT system in an actual ice model basin. For the cold room test undertaken in this study, a threepoint beam bending test was conducted for the specimens because a direct cantilever beam test was impossible in the miniature ice tank. A push-pull spring gauge was used to measure the flexural strength of the model ice specimens. The model ice specimens prepared for the three-point bending tests had the dimensions specified in the laboratory manuals [1][5].
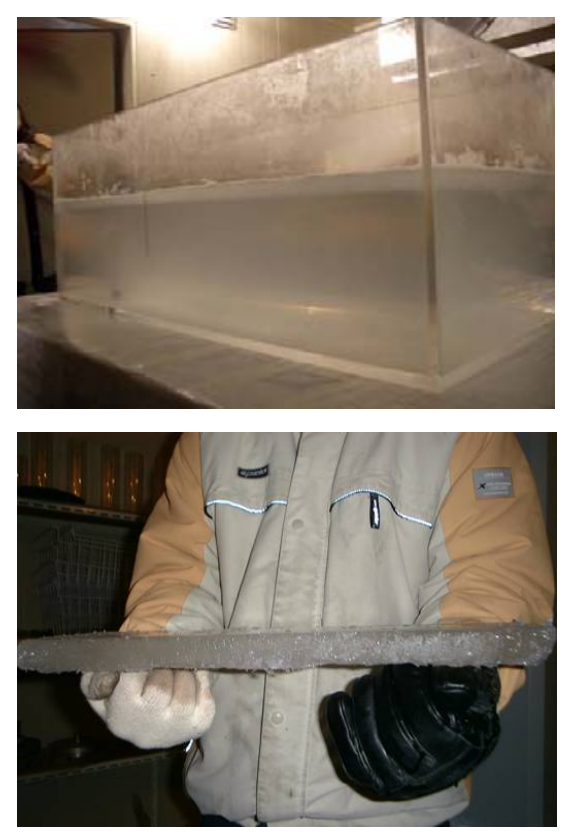

Photo. 1 Model ice sheet grown in the miniature ice tank

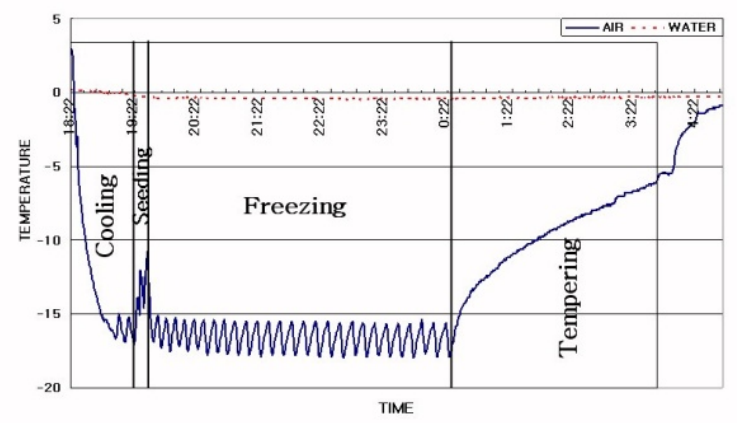

Fig. 1 Air and water temperature variation with time in the cold room

The length $(L)$ was five to six times the specimen thickness $(h)$ and the width $(B)$ was twice the thickness [6]. Since the model ice thickness grown in an actual ice model basin is normally about $2.5 \sim 5 \mathrm{~cm}$, the dimensions of the model ice specimens used in all the tests were, $h: B: L=25 \mathrm{~mm}: 50 \mathrm{~mm}: 125 \mathrm{~mm}$. In the three-point bending test, the flexural strength $\left(\sigma_{f}\right)$ was determined from the linear elastic beam theory, by $\sigma_{f}=\frac{3 P L}{2 B h^{2}}$, and the elastic modulus $(E)$, by $E=\frac{1}{4 B} \frac{P}{\delta}\left(\frac{L}{h}\right)^{3}$. The breaking load, $P$, of the 
model ice specimens was measured by a push-pull gauge. The elastic modulus of model ice was measured by the resonance frequency method for viscoelastic materials.

The uni-axial compressive strength of ice is also an important property because it controls the stress level at which the ice will crush. The standard size of the ice specimen in the compression test was chosen as $2.5 \mathrm{~mm} \times 2.5 \mathrm{~mm} \times 7.5 \mathrm{~mm}$, cut by a hand-saw, and then put into the compression test apparatus to measure the uni-axial compressive strength. This portable compression test apparatus was intended for use in the laboratory and also under outdoor conditions.

\subsection{Test results}

In order to obtain low strength and low stiffness for the model ice, it is necessary to use the warm-up process during the model ice preparation. The warm-up process produces ice structures that are weaken gradually, and therefore, the strength and stiffness of the model ice depend on the length of the warm-up period. Sugar was removed from the original EG/AD/S model ice, and with the same tests applied to both model ices. Fig.2 shows that the measured strengths of both model ice specimens decrease during the warm-up time. The data recorded for the EG/AD/S model ice was scattered slightly wider, compared those of the EG/AD model ice. The flexural strength test using the EG/AD model ice was performed every $2 \mathrm{hrs}$ during the warm-up process. The flexural strengths ranged from approximately 50 to $100 \mathrm{kPa}$.

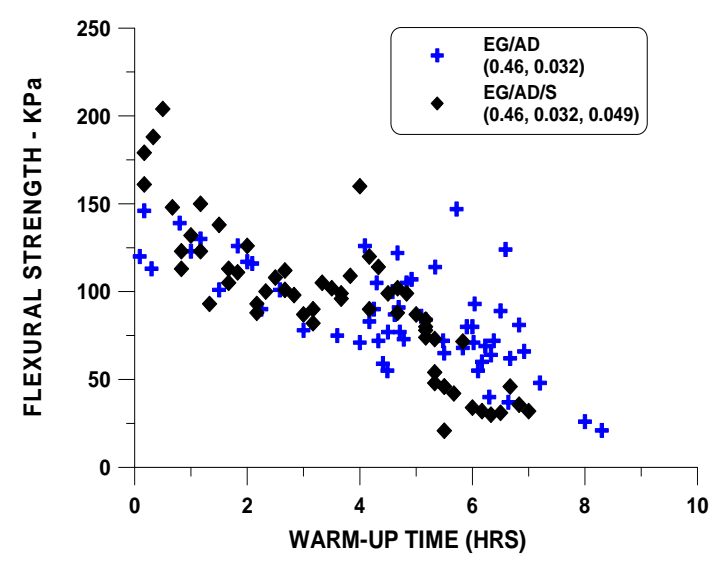

Fig. 2 Measured flexural strength of model ice specimen vs. warm-up time for the EG/AD/S and for the EG/AD model ices
The EG/AD/S model ice had a columnar (anisotropic) structure, which grew from the top to the bottom of the ice sheet in the ice tank. Timco [4] reported that sugar with a long chain organic molecule of high molecular weight inhibits the lateral growth of individual ice platelets in the ice sheet, which helps to produce fine-grained ice. However, it was found that the EG/AD model ice, without the sugar component, also had a columnar structure.

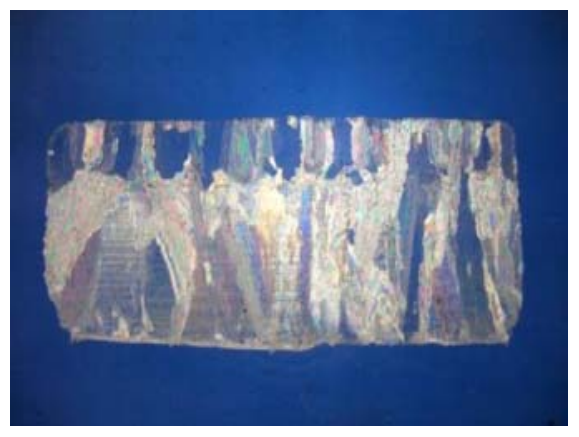

(a)EG/AD/S model ice

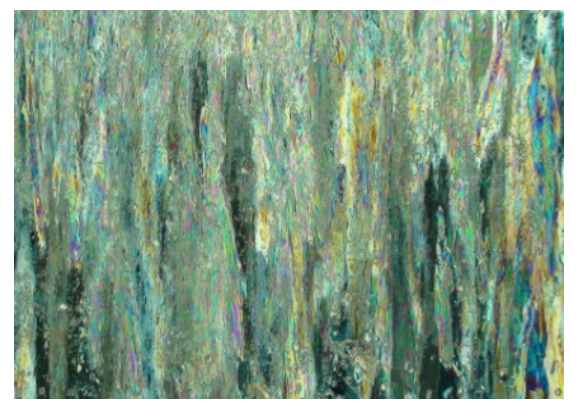

(b) EG/AD model ice

Photo. 2 Thin section photographs of model ice grown in the cold room

Photo. 2 shows thin section photographs of the model ice grown in the cold room. Table 1 summarizes the average values, after the 4 and $6 \mathrm{hr}$ warmup times, for the flexural strength and elastic modulus of the model ices measured from the tests. In Fig.3, the measured flexural strength values are plotted against the elastic modulus for the EG/AD/S and EG/AD model ices. Each point on the graph represents the result for an individual ice sheet. The data show a $E / \sigma_{f}$ ratio of about 2,000 for the flexural strength from 50 to $100 \mathrm{kPa}$, which was close enough to the published results [4]. It was necessary to check the $E / \sigma_{f}$ ratio was uniform over the entire range. 
Table 1. Measured mean values of the model ice elastic modulus and flexural strength

\begin{tabular}{|c|c|c|c|}
\hline Solution & $\begin{array}{c}\sigma_{f} \\
(\mathrm{kPa}) \\
\text { Mean }\end{array}$ & $\begin{array}{c}E \\
(\mathrm{MPa}) \\
\text { Mean }\end{array}$ & $E / \sigma_{f}$ \\
\hline $\begin{array}{c}\text { EG/AD/S } \\
\text { (EG 0.46\%, } \\
\begin{array}{c}\text { AD 0.032\%, } \\
\text { S 0.049\%) }\end{array}\end{array}$ & 65 & 147 & 2261 \\
\hline $\begin{array}{c}\text { EG/AD } \\
\text { (EG 0.46\%, } \\
\text { AD 0.032\%) }\end{array}$ & 61 & 128 & 2098 \\
\hline
\end{tabular}

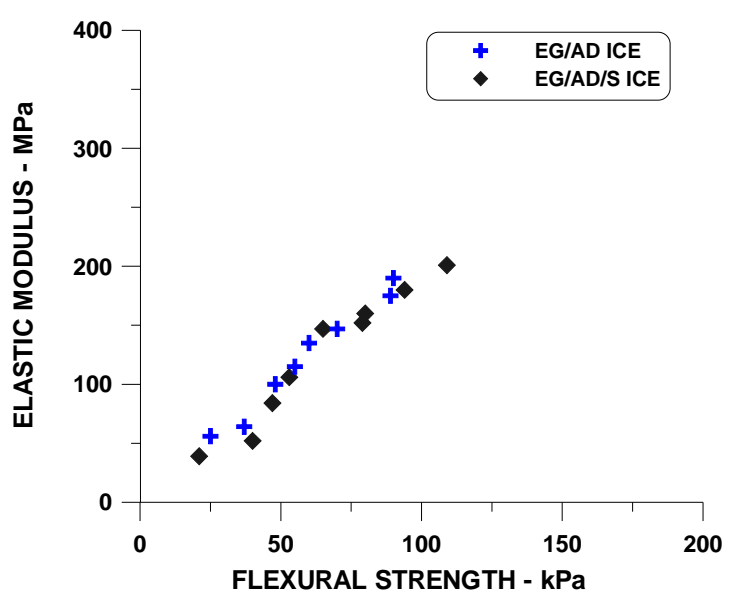

Fig. 3 Elastic modulus and flexural strength of EG/AD/S and EG/AD model ices measured from bending tests in the cold room

The results for the flexural strength against the compressive strength of the EG/AD model ice, measured during tests and previously published [4] were plotted for comparison (Table 2 and Fig. 4) and showed a good agreement. The uni-axial compressive strength decreased with decreasing flexural strength. It appeared that the mechanical behaviors of the uni-axial compressive strength and $E / \sigma_{f}$ for the EG/AD model ice were similar to those of the EG/AD/S model ice with respect to the anisotropic effect and warm-up process. It was expected that the compressive strength and flexural strength would become lower as the warm-up time became longer. It may be concluded that the EG/AD model ice can be used as a substitute for the EG/AD/S model ice in the MOERI ice tank.

Fig. 5 shows the flexural strength measured by pulling up, (i.e., placing the bottom of the ice sheet under tension for the cantilever beam but placing the top under tension for the simple beam), versus the flexural strength measured by pushing down, (i.e., placing the top of the ice sheet under tension for the cantilever beam but placing the bottom under tension for the simple beam).

Table 2. Measured flexural strength and compressive strength with respect to warm-up time

\begin{tabular}{|c|c|c|c|c|}
\hline \multirow{2}{*}{$\begin{array}{c}\text { Warm- } \\
\text { up } \\
\text { time }\end{array}$} & \multicolumn{4}{|c|}{ EG/AD Model Ice } \\
\cline { 2 - 5 } & \multicolumn{2}{|c|}{$\begin{array}{c}\text { Flexural } \\
\text { Strength(kPa) }\end{array}$} & \multicolumn{2}{c|}{$\begin{array}{c}\text { Compressive } \\
\text { Strength(kPa) }\end{array}$} \\
\cline { 2 - 5 } & $\begin{array}{c}\text { Mean } \\
\text { Value }\end{array}$ & Range & $\begin{array}{c}\text { Mean } \\
\text { Value }\end{array}$ & Range \\
\hline $\mathbf{0 h r}$ & 123.5 & $85 \sim 150$ & 256 & $150 \sim 320$ \\
\hline $\mathbf{2 h r}$ & 72.2 & $75 \sim 98$ & 193 & $120 \sim 240$ \\
\hline \multirow{2}{*}{$\mathbf{4 h r}$} & 61 & $40 \sim 82$ & 142 & $110 \sim 180$ \\
\hline \multirow{6}{*}{$\mathbf{6 h r}$} & 45 & $35 \sim 73$ & 115 & $80 \sim 130$ \\
\hline $\mathbf{8 h r}$ & 24 & $20 \sim 52$ & 75 & $65 \sim 120$ \\
\hline
\end{tabular}

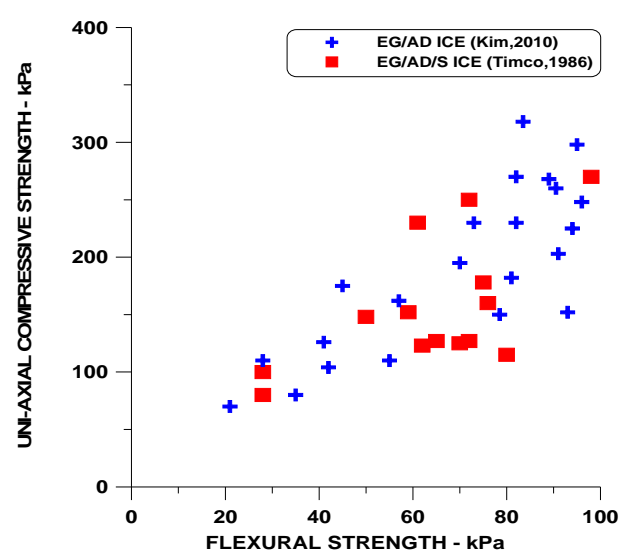

Fig. 4 Uni-axial compressive strength under horizontal loading versus flexural strength for $\mathrm{EG} / \mathrm{AD} / \mathrm{S}$ and $\mathrm{EG} / \mathrm{AD}$ model ices

Results for both the EG/AD/S [4] and EG/AD model ices tested in the cold room are shown in the figure. Defining a homogeneity factor as $H=\sigma_{f}(\uparrow) / \sigma_{f}(\downarrow)$ (in a cantilever beam) and $H=\sigma_{f}(\downarrow) / \sigma_{f}(\uparrow)$ (in a simple beam), it was shown that for these tests $H=0.69$ and 0.54 for the 
EG/AD/S and EG/AD model ices, respectively (for ice of $3 \mathrm{~cm}$ thickness).

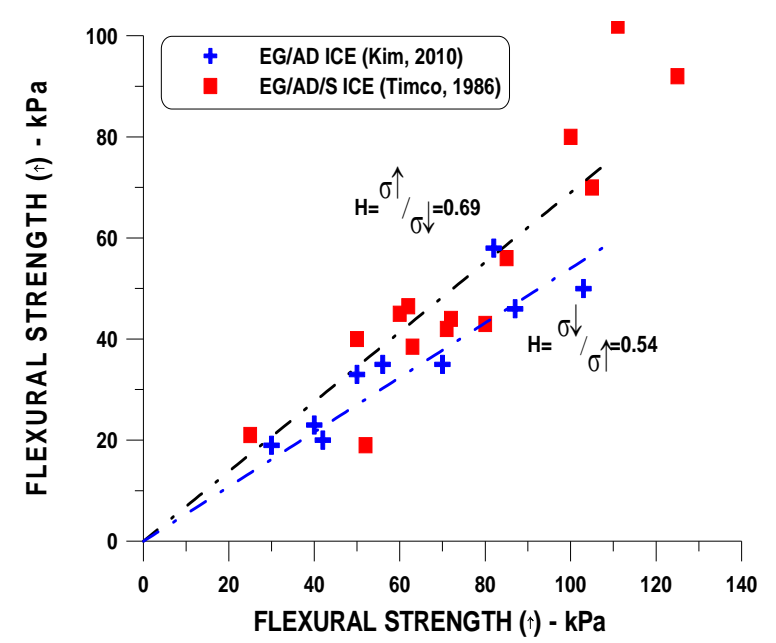

Fig. 5 Comparison of the flexural strength measured with both the top and the bottom under tension, for the EG/AD/S by Timco (1986) and the EG/AD ice tested in the cold room

No apparent strength dependence was observed for sea ice with loading direction, therefore, $\mathrm{H}=1.0$. In the cold room test, a significant difference according to the loading direction was observed. The flexural strength by pushing down was able to more easily break the ice than in the opposite direction. The reason for this difference was that the EG/AD model ice exhibited a strictly columnar, but not a single-layer structure compared the EG/AD/S model ice.

\section{Conclusions}

In this paper, possible substitutes were sought for the original EG/AD/S model ice for use in the MOERI ice tank. Long term use of sugar in model ice solution may cause a serious maintenance problem due to organic bacteria. In order to understand the influence of sugar in the original EG/AD/S model ice, the material properties of EG/AD/S and EG/AD model ices, such as flexural strength, compressive strength and elastic modulus were tested under cold room laboratory conditions.

The material properties of two types of model ice were found to be similar in their anisotropic and softening behaviors due to the warm-up process. Therefore, it may be concluded that the EG/AD model ice can be used as a substitute for the EG/AD/S model ice in the MOERI. However, an accurate calibration of the mechanical properties, and further study on the ratio of chemical additives required for preparation of a new model ice will be necessary.

\section{Acknowledgments}

Research fund provided by the Ministry of Knowledge and Economy, Korea, through the Industrial Strategic Technology Development Program (Grant No. 10033640) and also research support from the Korea Science and Engineering Foundation through the Advanced Ship Engineering Research Center (Grant No. ASERC R11-2002008-01002-0) are greatly acknowledged.

\section{References}

[1] ITTC, Testing and Extrapolation Methods - Ice Testing General Guidelines, ITTC Recommended Procedures, Ice Specialist Committee of 23rd ITTC (2002).

[2] K. Choi, J.H. Kim and Y.K Seo, An Experiment for the Mechanical Properties of Model Ice grown in a Cold Room, Proc. of the $19^{\text {th }}$ IAHR Ice Symposium, Vancouver, Canada, 2, (2008) 985-992.

[3] D.S. Spencer and G.W. Timco, CD Model Ice: A Process to Produce Correct Density Model Ice, Proc. of the $10^{\text {th }}$ IAHR Ice Symposium, Espoo, Finland, 2, (1990) pp 745-755.

[4] G.W. Timco, ED/AD/S: A New Type of Model Ice for Refrigerated Towing Tanks, Cold Regions Science and Technology, 12, (1986) 175-195.

[5] S.J. Jones, Ice Tank Test Procedures at the Institute for Marine Dynamics, NRC Report LM-AVR-20 (1993).

[6] G.W. Timco, On the Test Methods for Model Ice, Cold Regions Science and Technology, 4, (1981) 81-92.

[7] J.H. Kim and K. Choi, K. A Cold Room Experimental Study on the EG/AD Model Ice Properties, Proc. of the $9^{\text {th }}$ ISOPE Pacific/Asian Offshore Mechanics Symposium, Busan, Korea, (2010) 222225. 